
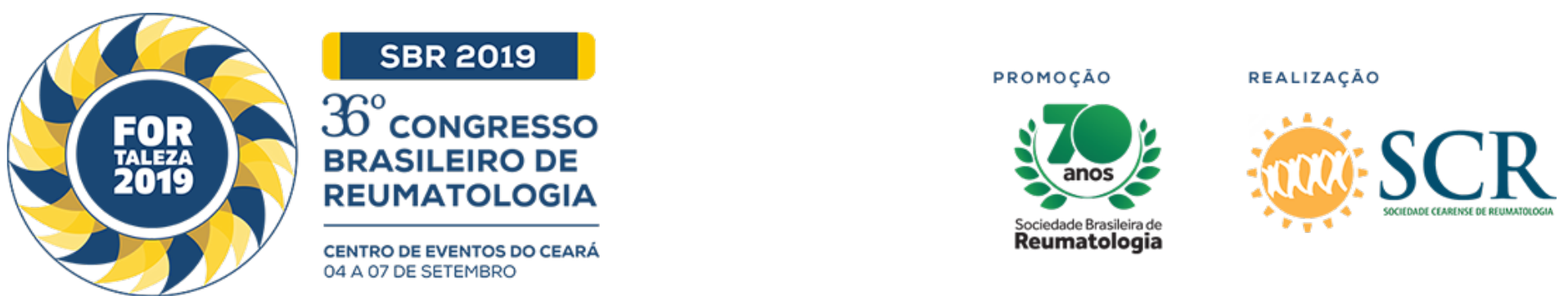

\title{
DISEASE ACTIVITY, LIFE QUALITY AND CLINICAL INDEXES AND INFLAMMATORY MARKERS IN PATIENTS WITH PSORIATIC ARTHRITIS AND THEIR CORRELATION WITH SACROILITIS
}

Antonio Helder Costa Vasconcelos (Universidade de Fortaleza, Fortaleza, CE, Brasil), Samily Cordeiro de Oliveira (Universidade Federal do Ceará, Fortaleza, CE, Brasil), Marcio Vale Braga (Universidade de Fortaleza, Fortaleza, CE, Brasil), Jailson Rodrigues Lopes (Instituto dr. José Frota, Fortaleza, CE, Brasil), Carlos Leite de Macedo Filho (Instituto dr. José Frota, Fortalez, CE, Brasil), Carlos Ewerton Maia Rodrigues (Universidade de Fortaleza; Universidade Federal do Ceará, Fortaleza, CE, Brasil)

\section{BACKGROUND}

Psoriatic arthritis (PsA) is a complex and heterogeneous inflammatory disease, which causes functional loss and reduction of life quality. These characteristics represent a challenge in the evaluation of patients with psoriatic arthritis, being essential the multifactorial evaluation in order to assess the real impact of the pathology and to establish a treatment goal. It is also crucial to assess inflammatory markers, such as erythrocyte sedimentation rate (ESR) and c-reactive protein (CRP); however, in comparison with other main spondyloarthritis, in PsA the laboratory markers are often not so clarifying. In this sense, this research proposes to evaluate the correlation of sacroiliitis findings in magnetic resonance imaging (MRI) with the said indexes and inflammatory markers.

\section{MATERIALS AND METHODS}

A cross-sectional study was carried out with forty-five patients with PsA who were accompanied at the outpatient clinic of rheumatology of a tertiary hospital in Fortaleza, Brazil, who underwent MRI examinations of the sacroiliac joints. Two independent evaluators observed the degree of concordance for sacroiliitis by the Kappa coefficient.

\section{RESULTS}

Regarding the indexes of disease activity in PsA, means and standard deviations were observed as it follow: DAS28PCR of $3,4 \pm 1,6$, DAS28VHS of $2,91 \pm 2,0$, BASDAI of 3,22 $\pm 2,1$, HAQ of 1,06 $\pm 0,7$, PASI of $2,0 \pm 2,9$ and MASES of $1,9 \pm 3,2$. The association of sacroiliitis with the indexes was also estimated with DAS28PCR $(p=0,358)$, DAS28VHS $(p=0,251)$, BASDAI $(p=0,389)$, HAQ $(p=0,420)$, PASI $(p=0,495)$ and MASES $(p=0,341)$. The $p$ value for the association for sacroiliitis and CRP and ESR was of, respectively, 0,028 and 0,494 . The statistical significance between CRP and sacroiliitis in PsA is also supported by the scientific literature, in which was found a $p$ value of 0,006 .

\section{CONCLUSION}

HAQ, PASI and MASES scores were low in the majority of patients. The activity indexes of PsA comparing patients with and without sacroiliitis in the magnetic resonance did not show a statistically relevant difference. The non-correlation of PASI with sacroiliitis in MRI is also confirmed by scientific literature. Increased CPR was associated with sacroiliitis, corroborating the importance of this laboratorial exam in the monitoring of the disease's activity, which suggests the routine testing of this marker in patients with PsA. This study didn't show a relevant association between ESR and the presence of sacroiliitis. 